\title{
ARTICLE
}

\section{Origin and evolution of the deep thermochemical structure beneath Eurasia}

\author{
N. Flament ${ }^{1} \uparrow$, S. Williams ${ }^{1}$, R.D. Müller ${ }^{1}$, M. Gurnis ${ }^{2} \&$ D.J. Bower ${ }^{3}$
}

A unique structure in the Earth's lowermost mantle, the Perm Anomaly, was recently identified beneath Eurasia. It seismologically resembles the large low-shear velocity provinces (LLSVPs) under Africa and the Pacific, but is much smaller. This challenges the current understanding of the evolution of the plate-mantle system in which plumes rise from the edges of the two LLSVPs, spatially fixed in time. New models of mantle flow over the last 230 million years reproduce the present-day structure of the lower mantle, and show a Perm-like anomaly. The anomaly formed in isolation within a closed subduction network $\sim 22,000 \mathrm{~km}$ in circumference prior to 150 million years ago before migrating $\sim 1,500 \mathrm{~km}$ westward at an average rate of $1 \mathrm{~cm}_{\text {year }}{ }^{-1}$, indicating a greater mobility of deep mantle structures than previously recognized. We hypothesize that the mobile Perm Anomaly could be linked to the Emeishan volcanics, in contrast to the previously proposed Siberian Traps.

\footnotetext{
${ }^{1}$ EarthByte Group, School of Geosciences, Madsen Building F09, University of Sydney, Sydney, New South Wales 2006, Australia. ${ }^{2}$ Seismological Laboratory, California Institute of Technology, Pasadena, California 91125, USA. ${ }^{3}$ Institute of Geophysics, Department of Earth Sciences, ETH Zürich, Sonneggstrasse 5, 8092 Zürich, Switzerland. †Present address: School of Earth and Environmental Sciences, University of Wollongong, Northfields Avenue, Wollongong, New South Wales 2522, Australia. Correspondence and requests for materials should be addressed to N.F. (email: nflament@uow.edu.au).
} 


\section{T} he long-wavelength structure of Earth's lowermost mantle is characterized by two large low-shear velocity provinces (LLSVPs) under Africa and the Pacific, $\sim 15,000 \mathrm{~km}$ (Fig. 1a) in diameter and $500-1,000 \mathrm{~km} \mathrm{high}^{1,2}$. In addition, a single, spatially small $(\sim<1,000 \mathrm{~km}$ in diameter, $\sim 500 \mathrm{~km}$ high $)$ deep mantle structure named the 'Perm Anomaly' was recently identified through seismic tomography ${ }^{3}$. The discovery of the Perm Anomaly poses fundamental questions about its dynamic relationship with the much larger LLSVPs, its uniqueness, its age and the formation of lower mantle structures in general. The structure of the lower mantle is important for reconstructions of the plate-mantle system ${ }^{4-8}$ in deep geological time because the reconstructed locations of most large igneous provinces (LIPs) and kimberlites over the past 320 million years (Myr) correlate with the edges of present-day LLSVPs, leading to the concept of a plume generation zone at LLSVP boundaries ${ }^{6}$. This concept has been used to build a model of absolute motion of tectonic plates over the Phanerozoic (past $540 \mathrm{Myr})^{8}$, under the assumptions that LLSVPs are fixed ${ }^{9}$ and non-deforming ${ }^{10}$ through time. However, numerical models suggest that the influence of sinking slabs ${ }^{11,12}$ should result in LLSVP deformation and motion ${ }^{13-16}$ over hundreds of million years. Additionally, measurements of differential splitting of SKS and SKKS seismic phases reveal anisotropy along the boundary of the African LLSVP ${ }^{17}$ and along the eastern boundary of the Perm Anomaly ${ }^{18}$, suggesting deformation is occurring on the edges of these structures. Finally, while SKS phases passing along the edge of LLSVPs suggest gradients in shear velocity that are too large to be explained by thermal variations alone $e^{19,20}$, how chemically distinct LLSVPs are from the rest of the mantle remains unclear ${ }^{21}$. Previous studies have shown that the largestscale structure of the lower mantle results from past subduction history ${ }^{11-13,15,16,22,23}$, without quantifying the geographic match between predicted and tomographic structures or the motion of individual thermochemical structures. Although some geodynamic models ${ }^{23,24}$ produce a Perm-like anomaly linked to the African LLSVP, its tectonic origin remains to be explained.

In this study, we report paleogeographically constrained forward global mantle flow models predicting a discrete structure similar in scale and geographical location to the recently discovered Perm Anomaly, and quantify the match between predicted and seismically inferred lower mantle structure across a series of mantle flow and tomography models. In the flow models, the Perm-like anomaly forms in isolation before 150 million years ago (Myr ago), within a long-lived, $\sim 22,000 \mathrm{~km}$-long, closed subduction network consisting of the Mongol-Okhotsk subduction zone to the west, northern Tethys subduction zone to the south, and east Asian subduction zone to the east. The models predict that the discrete Perm-like anomaly has coherently migrated westward at a rate of $1 \mathrm{~cm}_{\text {year }}{ }^{-1}$ over the last $150 \mathrm{Myr}$, which is incompatible with the hypothesis that lower mantle structures can be considered fixed and rigid over time. Because of its past mobility, the Perm Anomaly may not be linked to the Siberian Traps, but rather to the Emeishan volcanics.

\section{Results}

Predicted lowermost mantle temperature. We address the questions raised by the discovery of the Perm Anomaly through comparison of the lowermost mantle thermal structure predicted by forward global mantle flow models constrained by tectonic reconstruction ${ }^{25}$ (Methods) to tomography images. In dynamic models, slabs subducting deep into the mantle deform a basal layer, initially uniform, which is either thermal or thermochemical (Methods, Table 1). In the reference model (case 1, Table 1), predicted present-day temperature $\sim 200 \mathrm{~km}$ above the core-mantle boundary (CMB) is characterized by two large hightemperature regions under Africa and the Pacific and one smaller, spatially distinct high-temperature region north-east of the African Anomaly, under eastern Europe and western Russia (Fig. 1b). For case 1, the predicted present-day CMB and surface heat flow are respectively 10.4 TW and $40.3 \mathrm{TW}$, which is consistent with constraints ${ }^{26}$. The spatial extent of the large hightemperature regions is in first-order agreement with the position and shape of the African and Pacific LLSVPs in individual tomography models (for example, S40RTS (ref. 27), Fig. 1a) and in a vote map of tomography models ${ }^{3}$ (Fig. 1), and the predicted smaller structure under eastern Europe and western Russia matches the location of the Perm Anomaly in tomography (Fig. 1). Visual comparison suggests the reference model better fits the long-wavelength shape than similar models ${ }^{16}$. The edges of the model LLSVPs tend to be hotter than their interior (Fig. 1), which is consistent with a plume generation zone ${ }^{6}$.

Cluster analysis of mantle flow and tomography models. To make a more quantitative comparison between lower mantle temperature predicted by global geodynamic models with seismic velocity anomalies of selected tomography images, we use cluster analysis (Methods). Cluster analysis objectively classifies a set of points into groups of points with similar variations in a given property with depth. Following Lekic et al. ${ }^{3}$ we consider two clusters and depths between 1,000 and 2,800 km (Fig. 2). For S40RTS (ref. 27), the procedure reveals a low-velocity cluster below $\sim 2,400 \mathrm{~km}$ depth, in which seismic velocity anomalies are reduced to $-0.9 \%$, and a high-velocity cluster in which seismic velocity anomalies are increased to $+0.4 \%$ (Fig. $2 b$ ). For case 1f, which was seismically filtered ${ }^{28}$ (Methods) for direct comparison to tomography, a low-velocity and high-velocity cluster are also distinct below $\sim 2,400 \mathrm{~km}$ depth, although predicted anomalies are larger (down to $-1.2 \%$ and up to $+0.6 \%$, Fig. $2 \mathrm{~d}$ ). The geographic distribution of low-velocity clusters shows two large LLSVPs and a Perm-like anomaly in both S40RTS and case if (Fig. 2a,c), confirming that the extent and location of predicted deep mantle structures is compatible with seismic images. Given the small influence of seismic filtering, including on the extent and location of the Perm-like anomaly (Fig. 2c,e), we do not seismically filter other cases for which the clustering procedure reveals a high-temperature and a low-temperature cluster below $\sim 2,400 \mathrm{~km}$ depth (Fig. 2f).

Sensitivity of model success to parameters. We test the sensitivity to model parameters by considering 27 cases with varying Rayleigh number, initial model age, initial slab depth, viscosity, relative and absolute ${ }^{4,5,29}$ plate motions, and basal layer density (Table 1). To assess model success, we introduce a 'Perm Score' PS (Table 1) that visually characterizes model clusters; the method scores whether a predicted Perm-like anomaly is present and separate from the African LLSVP $(P S=2)$, present and linked to the African $\operatorname{LLSVP}(P S=1)$, or absent $(P S=0)$. A Perm-like anomaly is present and separate from the African LLSVP in 15 out of 27 cases. Moreover, this Perm-like anomaly is the only isolated, small anomaly that forms in all of these 15 cases; consequently there must be a specific cause for the generation of this unique feature. The Perm-like anomaly is separate at present-day for initial model age $>200 \mathrm{Myr}$ ago, initial slab depth $>800 \mathrm{~km}$, and when absolute plate motions are based on hotspot tracks ${ }^{4,29}$ and paleomagnetic data ${ }^{5}$ as opposed to mapping slab remnants from seismic tomography ${ }^{7}$ (Table 1). These results confirm the influence of initial conditions and subduction history on model results ${ }^{12}$, and we verified elsewher $^{23}$ that models initiated with LLSVPs in the initial 

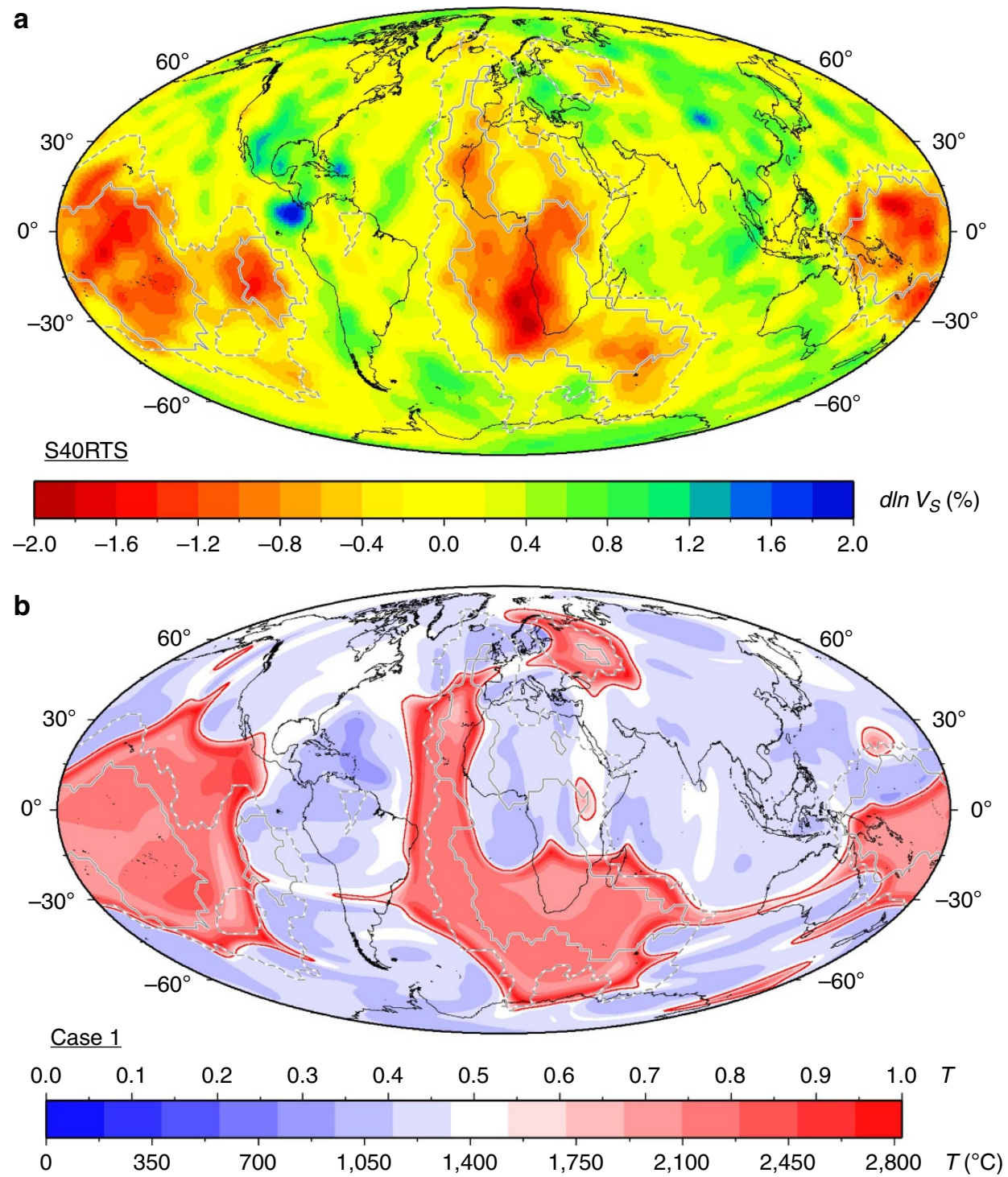

Figure 1 | Lower mantle structure inferred from seismic tomography and predicted by a mantle flow model. (a) Seismic velocity anomalies at 2,677 km depth for tomography model S4ORTS (ref. 27). (b) Predicted present-day mantle temperature at 2,677 km depth for case 1 . The solid gray contour indicates a value of five, and the dashed gray contour a value of one in a vote map for tomography models ${ }^{3}$. Present-day coastlines are shown in black.

condition are consistent with the present-day mantle structure. No Perm-like anomaly is predicted when the Rayleigh number Ra is ten times larger or 100 times smaller than in the reference case $\left(R a=7.8 \times 10^{\circ}\right)$.

To assess model success beyond the prediction of a Perm-like anomaly, we calculate the accuracy with which the global geographic distribution of predicted model clusters reproduces that of tomography clusters. This accuracy, defined as the ratio of successfully predicted areas to total area (Methods, Fig. 3), is calculated for distinct mantle flow and tomography models, each of which is based on different assumptions and delivers non-unique inferences of the true pattern of mantle structure. The accuracy varies between 0.54 and 0.81 across 27 model cases and seven tomography models (Methods, Fig. 4a), and is above random (0.5) even for the least successful models. For each case, we report the average accuracy for all seven tomography models, which ranges between 0.56 and 0.76 . Average accuracy decreases with decreasing initial model age, is $\leq 0.61$ when the initial model age is $100 \mathrm{Myr}$ ago or younger and when $R a$ is large $\left(7.8 \times 10^{8}\right)$, and is between 0.61 and 0.71 when the basal layer is purely thermal or $<2.54 \%$ chemically denser than ambient mantle (Fig. 4a; Table 1). The average accuracy is $\geq 0.71$ for all other cases. The average accuracy for GyPSuM-S (ref. 30) (0.65) is lower than for other tomography models (between 0.69 and 0.75 ), which might reflect that GyPSuM-S (ref. 30) is an inversion for geodynamic and mineral physics constraints in addition to the seismic constraints used in other tomography models.

Origin of the Perm Anomaly. Having established that the present-day lower mantle structure is well reproduced by mantle flow, we investigate the dynamics leading to the formation of the Perm-like anomaly. The model high-temperature clusters (Fig. 2e,f) correspond to temperatures that are $\sim 10 \%$ higher than ambient at $2,677 \mathrm{~km}$ depth (Fig. 1b). Following the evolution of temperature at $2,677 \mathrm{~km}$ depth in the reference case (Fig. 5a,c,e) reveals that despite its present-day proximity with the African LLSVP, the incipient Perm-like anomaly formed $\sim 190 \mathrm{Myr}$ ago centred on $100^{\circ} \mathrm{W} / 60^{\circ} \mathrm{N}$ (Fig. 5a), between three long-lived subduction systems: Mongol-Okhotsk along Eurasia 
Table 1 | Input parameters and output metrics of model cases.

\begin{tabular}{|c|c|c|c|c|c|c|c|c|c|c|c|c|}
\hline \multirow[t]{2}{*}{ Case } & \multicolumn{8}{|c|}{ Input } & \multicolumn{4}{|c|}{ Output } \\
\hline & $R a$ & $\eta_{0}(r)$ & $\delta \rho_{\mathrm{ch}}$ & $a_{0}$ (Myr ago) & $z_{\text {slab }}^{i}(\mathbf{k m})$ & $z_{90}^{i}(\mathrm{~km})$ & $\Gamma$ & $\boldsymbol{R}$ & PS & $\operatorname{Acc}_{\mathrm{G}}$ & $\operatorname{Acc}_{\mathrm{p}}$ & $a_{\mathrm{P}}$ (Myr ago) \\
\hline 1 & $7.8 \mathrm{E}+07$ & $1,1,1,10 \rightarrow 100$ & $4.24 \%$ & 230 & 1,400 & 425 & $\mathrm{~N}$ & C & 2 & 0.76 & 0.67 & 191 \\
\hline if & $7.8 \mathrm{E}+07$ & $1,1,1,10 \rightarrow 100$ & $4.24 \%$ & 230 & 1,400 & 425 & $\mathrm{~N}$ & C & 2 & 0.75 & 0.60 & 191 \\
\hline 2 & $7.8 \mathrm{E}+07$ & $1,1,1,10 \rightarrow 100$ & $3.39 \%$ & 230 & 1,400 & 425 & $\mathrm{~N}$ & C & 2 & 0.76 & 0.75 & 190 \\
\hline 3 & $7.8 \mathrm{E}+07$ & $1,1,1,10 \rightarrow 100$ & $2.54 \%$ & 230 & 1,400 & 425 & $\mathrm{~N}$ & C & 2 & 0.75 & 0.81 & 190 \\
\hline 4 & $7.8 \mathrm{E}+07$ & $1,1,1,10 \rightarrow 100$ & $1.70 \%$ & 230 & 1,400 & 425 & $\mathrm{~N}$ & C & 2 & 0.70 & 0.79 & 190 \\
\hline 5 & $7.8 \mathrm{E}+07$ & $1,1,1,10 \rightarrow 100$ & $0.85 \%$ & 230 & 1,400 & 425 & $\mathrm{~N}$ & C & 2 & 0.69 & 0.78 & 190 \\
\hline 6 & $7.8 \mathrm{E}+07$ & $1,1,1,10 \rightarrow 100$ & N/A & 230 & 1,400 & 425 & $\mathrm{~N}$ & C & 2 & 0.69 & 0.72 & 190 \\
\hline 7 & $7.8 \mathrm{E}+07$ & $1,1,1,10 \rightarrow 100$ & $4.24 \%$ & 230 & 1,400 & 425 & $N$ & $\mathbf{F}$ & 2 & 0.76 & 0.57 & 190 \\
\hline 8 & $7.8 \mathrm{E}+07$ & $1,1,1,10 \rightarrow 100$ & $4.24 \%$ & 200 & 1,400 & 425 & $\mathrm{~N}$ & $\mathbf{F}$ & 1 & 0.76 & $\mathrm{~N} / \mathrm{A}$ & 150 \\
\hline 9 & $7.8 \mathrm{E}+07$ & $1,1,1,10 \rightarrow 100$ & $4.24 \%$ & 150 & 1,400 & 425 & $\mathrm{~N}$ & $\mathbf{F}$ & 1 & 0.68 & $\mathrm{~N} / \mathrm{A}$ & 90 \\
\hline 10 & $7.8 \mathrm{E}+07$ & $1,1,1,10 \rightarrow 100$ & $4.24 \%$ & 100 & 1,400 & 425 & $\mathrm{~N}$ & $\mathbf{F}$ & 1 & 0.61 & $\mathrm{~N} / \mathrm{A}$ & 19 \\
\hline 11 & $7.8 \mathrm{E}+07$ & $1,1,1,10 \rightarrow 100$ & $4.24 \%$ & 50 & 1,400 & 425 & $\mathrm{~N}$ & $\mathbf{F}$ & 1 & 0.56 & $\mathrm{~N} / \mathrm{A}$ & $\mathrm{N} / \mathrm{A}$ \\
\hline 12 & $7.8 \mathrm{E}+07$ & $1,1,1,10 \rightarrow 100$ & $4.24 \%$ & 230 & 425 & 425 & $\mathrm{~N}$ & $\mathbf{F}$ & 1 & 0.77 & $\mathrm{~N} / \mathrm{A}$ & 129 \\
\hline 13 & $7.8 \mathrm{E}+07$ & $1,1,1,10 \rightarrow 100$ & $1.70 \%$ & 230 & 425 & 425 & $\mathrm{~N}$ & $\mathbf{F}$ & 1 & 0.72 & $\mathrm{~N} / \mathrm{A}$ & 139 \\
\hline 14 & $7.8 \mathrm{E}+07$ & $1,1,1,100$ & $4.24 \%$ & 230 & 425 & 425 & $\mathrm{~N}$ & C & 1 & 0.74 & $\mathrm{~N} / \mathrm{A}$ & 120 \\
\hline 15 & $7.8 \mathrm{E}+07$ & $1,1,10,100$ & $4.24 \%$ & $300^{\star}$ & 500 & 425 & $\mathbf{Y}$ & D & 1 & 0.75 & $\mathrm{~N} / \mathrm{A}$ & 220 \\
\hline 16 & $7.8 \mathrm{E}+07$ & $1,1,1,100$ & $4.24 \%$ & 230 & 800 & 425 & $\mathrm{~N}$ & C & 1 & 0.75 & $\mathrm{~N} / \mathrm{A}$ & 141 \\
\hline 17 & $7.8 \mathrm{E}+07$ & $1,0.1,1,100$ & $4.24 \%$ & 230 & 1,100 & 425 & $\mathrm{~N}$ & C & 2 & 0.75 & 0.54 & 190 \\
\hline 18 & $7.8 \mathrm{E}+07$ & $1,1,1,100$ & $4.24 \%$ & 230 & 1,200 & 660 & $\mathrm{~N}$ & B & 2 & 0.74 & 0.61 & 170 \\
\hline 19 & $7.8 \mathrm{E}+07$ & $1,1,1,100$ & $4.24 \%$ & 230 & 1,750 & 660 & $\mathrm{~N}$ & B & 2 & 0.73 & 0.59 & 190 \\
\hline 20 & $7.8 \mathrm{E}+05$ & $1,1,1,100$ & $4.24 \%$ & 230 & 1,200 & 425 & $\mathrm{~N}$ & C & 0 & 0.75 & $\mathrm{~N} / \mathrm{A}$ & $N / A$ \\
\hline 21 & $1.3 E+07$ & $1,1,1,10 \rightarrow 100$ & $4.24 \%$ & 230 & 1,200 & 660 & $\mathrm{~N}$ & C & 2 & 0.74 & 0.70 & 79 \\
\hline 22 & $7.8 \mathrm{E}+08$ & $1,1,1,10 \rightarrow 100$ & $4.24 \%$ & 230 & 1,200 & 660 & $\mathrm{~N}$ & C & 0 & 0.60 & $\mathrm{~N} / \mathrm{A}$ & $N / A$ \\
\hline 23 & $7.8 \mathrm{E}+07$ & $1,0.1 / 1,1,100$ & $4.24 \%$ & 230 & 1,400 & 425 & $\mathrm{~N}$ & C & 2 & 0.75 & 0.59 & 190 \\
\hline 24 & $7.8 \mathrm{E}+07$ & $1,0.1,1,100$ & $4.24 \%$ & 230 & 1,400 & 425 & $\mathrm{~N}$ & $\mathbf{E}$ & 1 & 0.75 & $\mathrm{~N} / \mathrm{A}$ & 190 \\
\hline 25 & $7.8 \mathrm{E}+07$ & $1,1,1,10 \rightarrow 100$ & $1.70 \%$ & 230 & 1,200 & 425 & $\mathrm{~N}$ & $\mathbf{A}$ & 2 & 0.69 & 0.78 & 200 \\
\hline 26 & $7.8 \mathrm{E}+07$ & $1,0.1,1,10 \rightarrow 100$ & $1.70 \%$ & 230 & 1,200 & 660 & $\mathbf{Y}$ & B & 2 & 0.71 & 0.78 & 190 \\
\hline 27 & $7.8 \mathrm{E}+07$ & $1,1,1,100$ & N/A & 230 & 1,200 & 425 & $\mathrm{~N}$ & C & 2 & 0.70 & 0.70 & 189 \\
\hline
\end{tabular}

$R a$ is the Rayleigh number, $\eta_{0}(r)$ is a pre-factor defined with respect to the reference viscosity $\eta_{0}$ for four layers: above $160 \mathrm{~km}$, between 160 and $310 \mathrm{~km}$ depth, between 310 and $660 \mathrm{~km}$ depth and below $660 \mathrm{~km}$ depth (where $10 \rightarrow 100$ indicates that the reference viscosity linearly increases with depth across the lower mantle, and $0.1 / 1$ indicates that the reference viscosity of the asthenosphere is 0.1 under oceanic plates and 1 under continental plates), $\delta \rho_{\mathrm{ch}}$ is the chemical density of the basal layer, derived from the buoyancy ratio $B, a_{0}$ is the age at which the model starts ( ${ }^{*}$ indicates that the same boundary conditions are repeated between 300 and $230 \mathrm{Myr}$ ago), $z_{\text {slab }}^{i}$ is the initial slab depth, $z_{90}^{i}$ is the depth from which the initial dip angle of slabs changes from $45^{\circ}$ to $90^{\circ}, \Gamma$ indicates whether a phase change is considered at $660 \mathrm{~km}$ depth, $R$ is the reconstruction, PS is a score indicating with value 0 if a Perm-like anomaly is not predicted, 1 , if it is, and 2 if it is predicted and separate from the African LLSVP, Acc $\mathrm{G}$ is the global accuracy, Accp is the accuracy in the Perm region, and $a_{\mathrm{p}}$ is the age from which the Perm-like anomaly exists. Parameters in bold are different from the reference case. See Methods for more details.

(geodynamically preferable than along Central $\mathrm{Asia}^{31}$ ) to the west, northern Tethys to the south, and east Asia to the east (Fig. 5a,b). In this tectonic scenario ${ }^{32,33}$, subduction to the west of the Perm-like anomaly ceases when the Mongol-Okhotsk Ocean closes $150 \mathrm{Myr}$ ago. The Perm-like anomaly then migrates $\sim 1,500 \mathrm{~km}$ westward as pushed by descending slabs ${ }^{12,15,23}$ subducting under east Asia (Fig. 5c-f). The coherent translation of the discrete, Perm-like anomaly allows us to estimate an average motion rate of $1 \mathrm{~cm}^{-1} \mathrm{car}^{-1}$ over the last $150 \mathrm{Myr}$. This ongoing westward flow is compatible with SKS-SKKS splitting measurements revealing anisotropy with a fast east-west direction in the lowermost mantle under eastern Europe and western Russia ${ }^{18}$, potentially due to lattice preferred-orientation of post-perovskite ${ }^{34}$. Moreover, the prediction is consistent with deformation on the eastern boundary of the Perm Anomaly and the presence of high seismic velocity structures to the east of the Perm Anomaly that also reveal anisotropy in SKS-SKKS splitting measurements ${ }^{18}$. Together with seismic observations ${ }^{18}$ and previous models ${ }^{13-16}$, our results challenge the long-term fixity and rigidity of deep-mantle thermochemical structures.

\section{Discussion}

The genesis of the Perm-like anomaly within a long-lived, closed subduction network with a perimetre $\sim 22,000 \mathrm{~km}$ (Fig. $5 \mathrm{a}$ ) could explain why a single small LSVP ${ }^{18}$ is observed seismically, and why only one isolated thermochemical pile forms in our models. Although the geometry and timing of past plate boundaries is increasingly uncertain back in geological times due to decreasing amounts of preserved ocean floor ${ }^{35}$, this tectonic setting is unique for the last 230 Myr. We find that the Perm-like anomaly is only separate at present if slabs are inserted to depths $>800 \mathrm{~km}$ $(P S=2$ in Table 1) in the initial condition at $230 \mathrm{Myr}$ ago. This suggests that the subduction network would have been established at the latest between $\sim 330$ and $\sim 280 \mathrm{Myr}$ ago, depending on slab sinking rates ${ }^{7}$. For the reference case, the present-day Perm-like anomaly is chemically distinct $(\sim 550 \mathrm{~km}$ in thickness based on $50 \%$ dense material), high temperature ( $\sim 850 \mathrm{~km}$ in thickness based on mantle $20 \%$ hotter than ambient) and may actively contribute to mantle upwelling (Fig. 5f). The predicted chemical anomaly is consistent with the $\sim 500 \mathrm{~km}$ thickness of the Perm Anomaly inferred from seismic images $^{3}$, but the thermal anomaly may be overestimated in the model. In contrast to models in which the Perm-like anomaly is similar to LLSVPs (Fig. 2d), global seismic models have not reported shear-velocity anomalies in the Perm Anomaly that are as low as in the LLSVPs ${ }^{3}$ (Fig. 2b), although caution must be exercised as the amplitudes of seismic anomalies are often poorly constrained tomographically ${ }^{36}$. One possibility to explain the apparent smaller shear-velocity reduction in the Perm Anomaly ${ }^{3}$ (Fig. 2b) is that it could be compositionally different from the LLSVPs: decreasing the density of the basal layer results in a better match of the Perm Anomaly, but a poorer global match (Figs 3 and 4; Table 1).

Our reconstructions of past mantle flow link the formation of the Perm Anomaly to the history of subduction around east and 

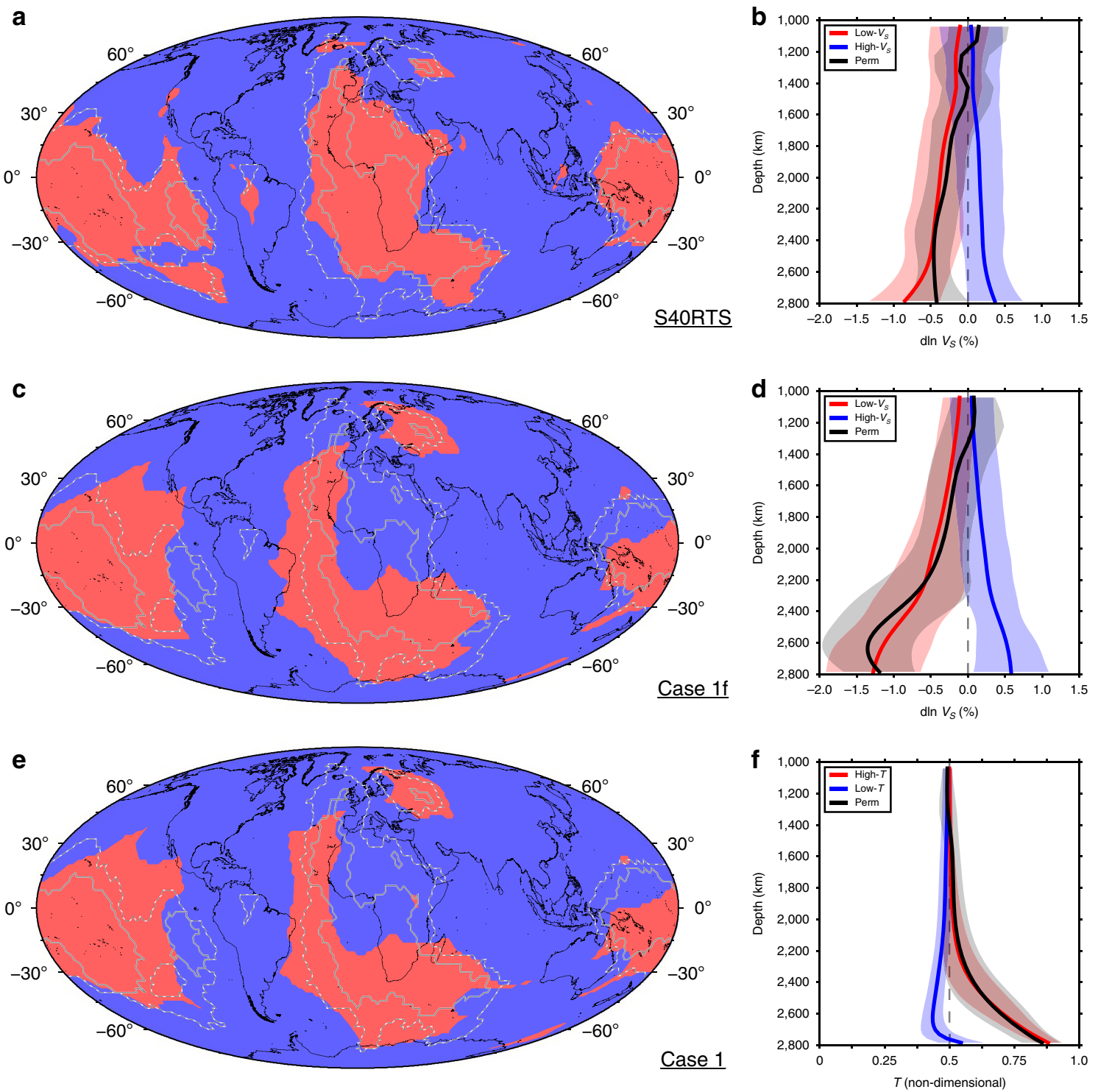

Figure 2 | Clustering of lower mantle seismic tomography and predicted mantle temperature. (a) High-velocity (blue) and low-velocity (red) regions between 1,000 and 2,800 km depth for seismic tomography model S4ORTS (ref. 27). (b) Seismic velocity profiles in high-velocity and low-velocity regions for S4ORTS (ref. 27). The solid curves are the mean, and the transparent envelopes are the associated standard deviation, of the global low-velocity cluster (red), global high-velocity cluster (blue) and low-velocity cluster for the separate Perm-like anomaly (black). (c,e). Same as a but for seismically filtered ${ }^{28}$ case $1 f(\mathbf{c})$ and case $1(\mathbf{e})$. (d, f). Same as $\mathbf{b}$ but for seismically filtered ${ }^{28}$ case $1 f(\mathbf{d})$ and case $1(\mathbf{f})$. In $\mathbf{a}, \mathbf{c}, \mathbf{e}$, the solid gray contour indicates a value of five and the dashed gray contour a value of one in a vote map for tomography models ${ }^{3}$. Present-day coastlines are shown in black.

central Asia between 230 and $150 \mathrm{Myr}$ ago. The formation of the Perm Anomaly would have occurred several tens of million years after this subduction network was established, as slabs slowly sank. The Perm Anomaly appears between 220 and 80 Myr ago depending on the Rayleigh number, the initial slab depth and the initial model age (Methods, Table 1). Although tectonic uncertainties increase back in geological time, some reconstructions suggest that a closed network of subduction zones $\sim 20,000 \mathrm{~km}$ in perimeter might have been established around the MongolOkhotsk Ocean $410 \mathrm{Myr}$ ago ${ }^{37}$, in which case the Perm Anomaly might have existed for much of the Phanerozoic. Structures similar to the Perm Anomaly are likely to have existed earlier in Earth's history, controlled by past subduction zone configurations.

Conceptual $^{6}$ and geodynamic ${ }^{22,23,24}$ models suggest that plumes mostly rise from deep thermochemical structures to form LIPs at Earth's surface. The reconstructed location of the 258-Myr ago Emeishan LIP falls within the network formed by the Mongol-Okhotsk, northern Tethys, and East Asia subduction zones between 230 and $150 \mathrm{Myr}$ ago $^{33}$ (Fig. 5a). In contrast, the reconstructed location of the $\sim 251 \mathrm{Myr}$ ago Siberian Traps does not reconstruct within this subduction network between 230 and $150 \mathrm{Myr}$ ago (the reconstructed location of the Siberian Traps is outside the region shown in Fig. 5a). Because the models show that the Perm anomaly originated within this subduction network, we propose that the Emeishan LIP is a possible product of the Perm Anomaly, in contrast to the Siberian Traps ${ }^{3,8}$. These competing hypotheses could be tested in future convection models including mantle plumes ${ }^{23}$, contrary to the models presented here, and based on tectonic reconstructions extending into the Paleozoic, but that do not assume that the Emeishan LIP originated from the Pacific LLSVP, contrary to existing reconstructions ${ }^{8,37}$. 
a

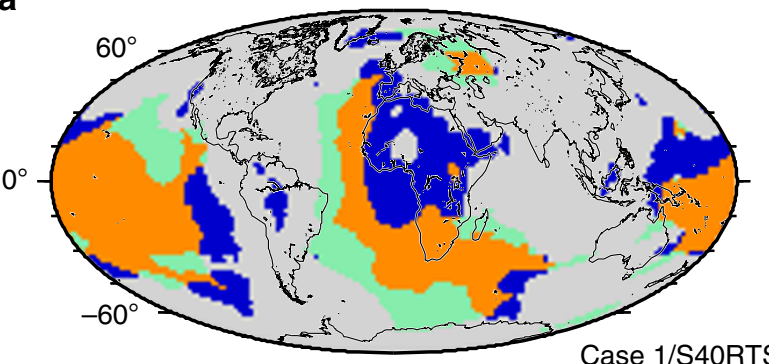

Case 1/S40RTS

C

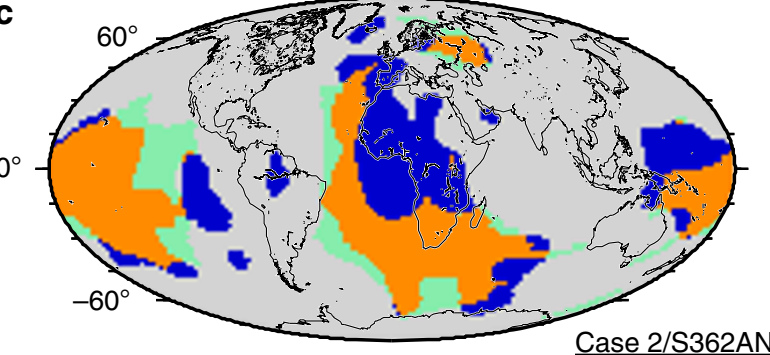

e

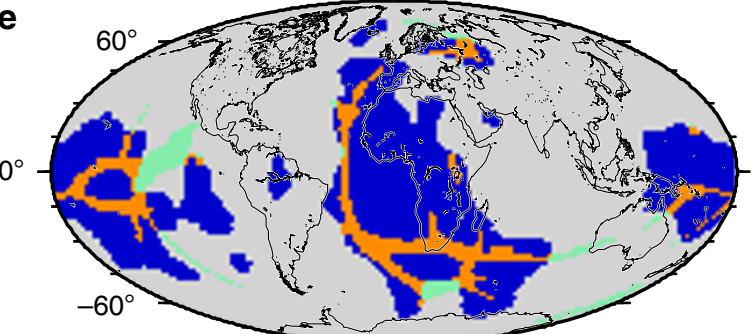

b
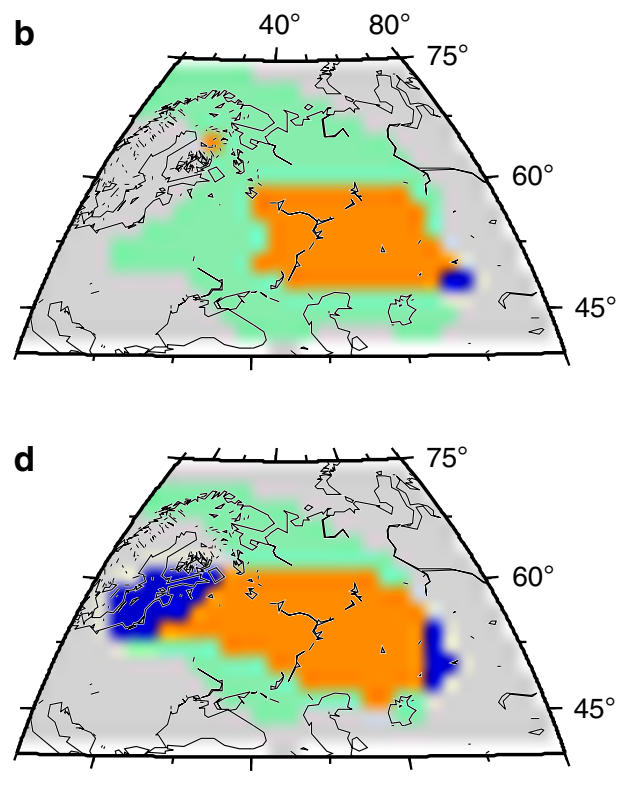

f

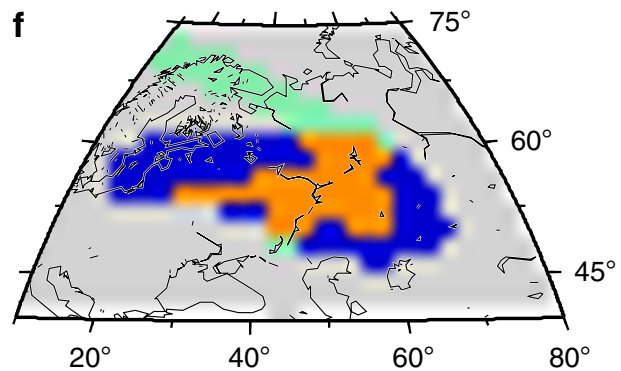

Figure 3 | Spatial match between predicted lower mantle structure and that inferred from seismic tomography. Orange (true positive) indicates hightemperature cluster for the model and low-velocity cluster for the tomography, gray (true negative) indicates low-temperature cluster for the model and high-velocity cluster for the tomography, green (false positive) indicates high-temperature cluster for the model and high-velocity cluster for the tomography and blue (false negative) indicates low-temperature cluster for the model and low-velocity cluster for the tomography. Present-day coastlines are shown in black. Results are shown for case 1 and S4ORTS (ref. 27) (a,b), case 2 and S362ANI (ref. 38) (c,d), e,f, and case 5 and S362ANI (ref. 38) (e,f). b,d,f $\mathbf{f}$ show results in the region between $10^{\circ}-80^{\circ} \mathrm{E}$ and $40^{\circ}-75^{\circ} \mathrm{N}$ that includes the Perm Anomaly.

The tectonic configuration of a $\sim 22,000 \mathrm{~km}$ network of longlived ( $>80 \mathrm{Myr}$ ) subduction zones around east and central Asia before 150 Myr ago, unique in the last 200 Myr ago, led to the formation of a single, well-defined and isolated thermo-chemical anomaly. Numerical models reproduce this past natural experiment, and the coherent westward motion of the discrete Perm-like anomaly allows us to quantify an average motion of $1 \mathrm{~cm}$ year ${ }^{-1}$ since the Mongol-Okhotsk Ocean closed 150 Myr ago.

\section{Methods}

Paleogeographically constrained dynamic Earth models. We solve the equations for incompressible convection in a spherical domain with finite-elements using the code Citcoms $^{39}$, modified as described in ref. 25 to progressively assimilate the velocity of tectonic plates, the age of the ocean floor and the location and polarity of subduction zones determined in one million year intervals from global plate tectonic reconstructions $s^{32,33}$ with continuously closing plates ${ }^{40}$. This semi-empirical approach ensures our computations represent Earth's imposed tectonic history, allowing us to reconstruct the history of deep mantle flow over the last 230 Myr. This approach is guided by the current intractability of computing time-dependent models of Earth's plate-mantle system with the resolution required to dynamically achieve tectonic-like features, including one-sided subduction ${ }^{41}$ and conserve the energy of the system simultaneously. Here we give a summary of the governing parameters and model setup that are further described in refs 25,42 .

The vigour of convection is defined by the Rayleigh number $R a=\left(\alpha_{0} \rho_{0} g_{0} \Delta T h_{\mathrm{M}}^{3}\right) /\left(\kappa_{0} \eta_{0}\right)$, where $\alpha_{0}=3 \times 10^{-5} \mathrm{~K}^{-1}$ is the coefficient of thermal expansion, $\rho_{0}=4,000 \mathrm{~kg} \mathrm{~m}^{-3}$ is the density, $g_{0}=9.81 \mathrm{~m} \mathrm{~s}^{-2}$ is the gravity acceleration, $\Delta T=2,825 \mathrm{~K}$ is the temperature change across the mantle, $h_{\mathrm{M}}=2,867 \mathrm{~km}$ is the thickness of the mantle, $\kappa_{0}=1 \times 10^{-6} \mathrm{~m}^{2} \mathrm{~s}^{-1}$ is the thermal diffusivity, $\eta_{0}=1 \times 10^{21} \mathrm{~Pa} \mathrm{~s}$ is the viscosity, and the subscript ' 0 ' indicates reference values. With the values listed above, $\mathrm{Ra}=7.8 \times 10^{7}$. These values are varied between model cases such that Ra varies between $7.8 \times 10^{5}$ and $7.8 \times 10^{9}$ (Table 1).

We approximate the Earth's mantle as a Newtonian fluid in which viscosity varies with depth and temperature following $\eta=\eta_{0}(r) \exp \left\{E_{\eta} /\left[R\left(T+T_{\eta}\right)\right]-E_{\eta} /\left[R\left(T_{\mathrm{b}}+T_{\eta}\right)\right]\right\}$, where $\eta_{0}(r)$ is a pre-factor defined with respect to the reference viscosity $\eta_{0}$ for four layers: above $160 \mathrm{~km}$, between 160 and $310 \mathrm{~km}$ depth, between 310 and $660 \mathrm{~km}$ depth and below $660 \mathrm{~km}$ depth, in the lower mantle. Values of $\eta_{0}(r)$ for each layer are given as commaseparated lists in Table 1 , where ' $10 \rightarrow 100$ ' indicates that the reference viscosity linearly increases with depth from 10 to 100 throughout the lower mantle, and $0.1 / 1$ indicates that the reference viscosity of the asthenosphere is 0.1 under oceanic plates and 1 under continental plates. $E_{\eta}$ is the activation energy taken as $100 \mathrm{~kJ} \mathrm{~mol}^{-1}$ in the upper mantle and $30 \mathrm{~kJ} \mathrm{~mol}^{-1}$ in the lower mantle, $R=8.31 \mathrm{~J} \mathrm{~mol}^{-1} \mathrm{~K}^{-1}$ is the universal gas constant, $T$ is the dimensional temperature, $T_{\eta}=452 \mathrm{~K}$ is a temperature offset and $T_{\mathrm{b}}=1,685 \mathrm{~K}$ is the ambient mantle temperature. The activation energy and temperature offset are chosen to limit variations in viscosity to three orders of magnitude across the range of temperatures without imposing a yield stress. Such lateral viscosity contrasts are lower than expected to occur within the solid Earth ${ }^{41}$, but they can be computed with a resolution that allows us to compute time-dependent mantle flow models. A phase change $\Gamma$ at $660 \mathrm{~km}$ depth, as described in Flament et al ${ }^{42}$ is considered in some model cases (Table 1).

For the initial condition and progressive data assimilation, the thickness and temperature of the lithosphere are derived using a half-space cooling model and the synthetic age of the ocean floor ${ }^{25}$, and simplified tectonothermal ages for the 
a

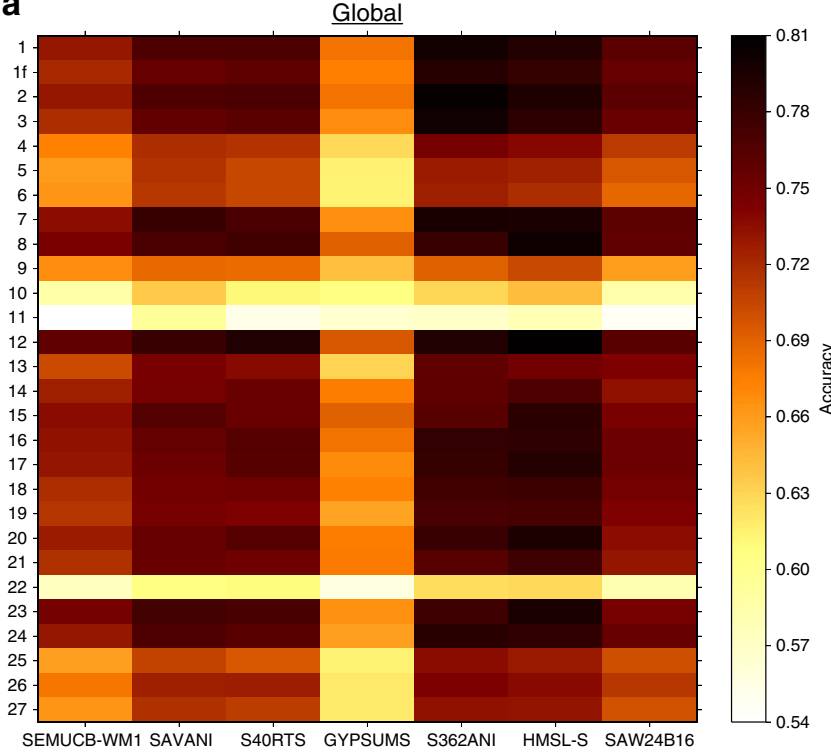

b

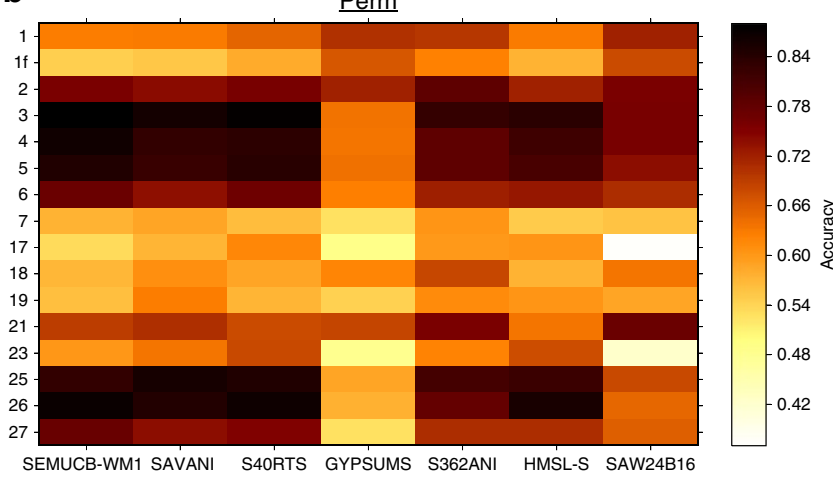

Figure 4 | Quantitative match between predicted lower mantle structure and seismic tomography models. Accuracy (true positive area plus true negative area over total area), with which the geographical distribution of clusters of mantle temperature between 1,000 and 2,800 km depth predicted by 27 mantle flow model cases (case $1 f$ is seismically-filtered case 1) reproduce the geographical distribution of clusters of seismic velocity anomalies between 1,000 and 2,800 km depth for seven S-wave tomography models. (a) global accuracy, (b) accuracy in the region between $10^{\circ}-80^{\circ} \mathrm{E}$ and $40^{\circ}-75^{\circ} \mathrm{N}$ that includes the Perm Anomaly, for cases predicting a Perm-like anomaly separate from the model African LLSVP (PS $=2$ in Table 1). See Table 1 for values of the global and regional accuracies averaged over the seven considered tomography models.

continental lithosphere ${ }^{42}$. The global thermal structure of slabs is constructed from the location of subduction zones and from the age of the ocean floor $^{25}$. The global thermal structure of the lithosphere and of subducting slabs is assimilated in the dynamic models in $1 \mathrm{Myr}$ increments, to $350 \mathrm{~km}$ depth at subduction zones ${ }^{25}$. In the initial condition, subduction zones are inserted in the mantle assuming a descent rate of $3 \mathrm{~cm}_{\text {year }}{ }^{-1}$ in the upper mantle and $1.2 \mathrm{~cm}_{\text {year }}-1$ in the lower mantle ${ }^{7}$. Subduction zones that appear during the model are progressively inserted to $350 \mathrm{~km}$ depth based on the age of subduction initiation and on the plate convergence rate.

The initial condition, derived from the tectonic reconstruction at $230 \mathrm{Myr}$ ago, includes a basal layer just above CMB, which is either purely thermal or thermochemical (Table 1). The layer is $113 \mathrm{~km}$ thick, which represents $2 \%$ of the volume of the mantle, consistent with the seismically inferred value ${ }^{2}$. The composition of that layer is modeled using tracers ${ }^{42}$ and its chemical density $\delta \rho_{\mathrm{ch}}$ is varied between $+0.85 \%$ and $+4.24 \%$ (Table 1 ) by changing the buoyancy ratio $B=\delta \rho_{\mathrm{ch}} /\left(\rho_{0} \alpha_{0} \Delta T\right)$ between 0.1 and 0.5 , with increment 0.1 . Slabs are initially inserted down to a depth of either $z_{\text {slab }}^{i}$ (varied between $425 \mathrm{~km}$ and $1,750 \mathrm{~km}$; Table 1), or to the depth derived from their initiation age and sinking rates if that depth is shallower than $z_{\text {slab }}^{i}$, with a dip of $45^{\circ}$ down to $z_{90}^{i}$ and a dip of $90^{\circ}$ below $z_{90}^{i}$ (either 425 or $660 \mathrm{~km}$; Table 1). Slabs are initially twice as thick in the lower mantle compared with their thickness in the upper mantle, to account for advective thickening in the more viscous lower mantle.

The model consists of $129 \times 129 \times 65 \times 12 \approx 13 \times 10^{6}$ nodes, which with a radial mesh refinement that gives average resolutions of $\sim 50 \times 50 \times 15 \mathrm{~km}$ at the surface, $\sim 28 \times 28 \times 27 \mathrm{~km}$ at the $\mathrm{CMB}$, and $\sim 40 \times 40 \times 100 \mathrm{~km}$ in the mid-mantle

We investigate the influence of relative and absolute plate motions across five global tectonic reconstructions ( $R$ in Table 1). Reconstruction $\mathrm{A}$, which uses the absolute plate motions of ONeill et al. ${ }^{4}$ between 0 and $100 \mathrm{Myr}$ ago and that of Steinberger and Torsvik ${ }^{5}$ before $100 \mathrm{Myr}$ ago, is described in Seton et al. ${ }^{32}$ and extended from the last $200 \mathrm{Myr}$ ago to the last $230 \mathrm{Myr}$ ago $^{33}$. Continuouslyclosing plate polygons ${ }^{40}$ and ages of the ocean floor ${ }^{32,33}$, necessary to assimilate plate reconstructions in mantle flow models with the method described in Bower et al. ${ }^{25}$ are available to us back to $230 \mathrm{Myr}$ ago. Reconstruction B includes changes to relative plate motions in the Arctic region ${ }^{33}$ and uses the absolute plate motions of Torsvik et al. ${ }^{29}$ between 0 and $70 \mathrm{Myr}$ ago and that of Steinberger and Torsvik ${ }^{5}$ before $105 \mathrm{Myr}$ ago, with interpolation between the two absolute plate motion models between 70 and $105 \mathrm{Myr}$ ago. Reconstruction $\mathrm{C}$ includes changes to relative plate motions in Southeast $\mathrm{Asia}^{33}$ compared with reconstruction $\mathrm{B}$. Reconstruction $\mathrm{D}$ includes changes to relative plate motions in the western Tethys ${ }^{33}$ compared with reconstruction C. Reconstruction E is based on the absolute plate motions of van der Meer et al..$^{7}$ and on the same relative plate motions as reconstruction D. Reconstruction $\mathrm{F}$ uses the same absolute plate motion model as reconstruction $\mathrm{B}$, and relative plate motions as described in Muller et $\mathrm{al}^{33}$

Cluster analysis of lower mantle structure. We use cluster analysis to objectively classify a set of points on the surface into groups of points with similar variations in a given property with depth. For each flow model case (or tomography model), temperature (or seismic velocity) profiles are treated as 196,596 independent vectors of 31 coordinates specifying the temperatures (or seismic velocities) sampled at 31 depths between 1,000 and $2,800 \mathrm{~km}^{3}$, with an average resolution of $58 \mathrm{~km}$. Each vector corresponds to equally-spaced locations on Earth's surface (average distance $\sim 0.45^{\circ}$ ). The vectors are grouped into two clusters using $k$-means clustering ${ }^{43}$, a procedure that keeps the variance in squared Euclidean distance between vectors small within each cluster. We use the scientific Python implementation of the $k$-means algorithm (http://docs.scipy.org/doc/scipy/ reference/generated/scipy.cluster.vq.kmeans2.html). The average and standard deviation of temperature profiles for each cluster are shown in Fig. 2 for the reference case, along with the average and standard deviation of temperature profiles for the high-temperature cluster in the Perm region.

Seismic filtering. We seismically filter our reference case 1 following Ritsema et $a l .{ }^{28}$ to verify if lower mantle features apparent in the model temperature field would be resolved by global tomography ${ }^{27}$. We consider that both temperature and composition variations cause variations in shear velocity. For the thermal contribution, we determine wave speed variations $\left(\mathrm{d} V_{\mathrm{S}}\right)$ scaling departures from average temperature at each depth $(\mathrm{d} T)$ using $\mathrm{d} V_{\mathrm{S}} / \mathrm{d} T=-7.0 \times 10^{-5} \mathrm{~km} \mathrm{~s}^{-1} \mathrm{~K}^{-1}$ (ref. 44). For the chemical contribution, we determine wave speed variations $\left(\mathrm{d} V_{S}\right)$ from variations in the composition field at each depth $(\mathrm{d} C)$ using $\mathrm{d} V_{\mathrm{S}} / \mathrm{d} C=4 \times \delta \rho_{\mathrm{ch}}$ (ref. 45), where $\delta \rho_{\mathrm{ch}}$ is the density of the chemically distinct basal layer. Thermal and compositional contributions to wave speed variations are jointly considered following $\mathrm{d} V_{\mathrm{s}}=\mathrm{d} V_{\mathrm{s}} / \mathrm{d} T \times \mathrm{d} T+f_{\mathrm{c}} \times \mathrm{d} V_{\mathrm{s}} / \mathrm{d} C \times \mathrm{d} C$, where $f_{\mathrm{c}}=0.05$ is the contribution of composition to total wave speed anomalies.

Quantification of model success. We quantify how well the clusters obtained for each model case reproduce the global geographic distribution of clusters obtained for global S-wave tomography models ${ }^{27,30,38,46-49}$ by computing the accuracy $\mathrm{Acc}=(\mathrm{TP}+\mathrm{TN}) / A$, where TP is the area of true positives, TN the area of true negatives and $A$ the total area. Three examples of the spatial distribution of true positives, true negatives, false positives and false negatives with respect to tomography models are shown in Fig. 3. The accuracy is computed for each model case, both globally and in the region between $10^{\circ}-80^{\circ} \mathrm{E}$ and $40^{\circ}-75^{\circ} \mathrm{N}$ that includes the Perm Anomaly, against seven global S-wave tomography models (Fig. 4): SAW24B16 (ref. 46), HMSL-S (ref. 47), S362ANI (ref. 38), GyPSuM-S (ref. 30), S40RTS (ref. 27), Savani (ref. 48), SEMUCB-WM1 (ref. 49). Values of the global and regional accuracies averaged over the seven tomography models are reported in Table 1

Age of the Perm-like anomaly. We report the age $a_{\mathrm{p}}$ from which the separate Perm-like anomaly is $>190 \mathrm{~km}$ thick (based on a mantle temperature $10 \%$ higher than ambient, and with model output every $\sim 10 \mathrm{Myr}$ ) in Table 1.

Data availability. Maps of the geographic distribution of tomography and flow model clusters reported are available at https://www.earthbyte.org/originevolution-perm-anomaly/. The computer code that supports the findings of this study is available from the corresponding author upon reasonable request. 


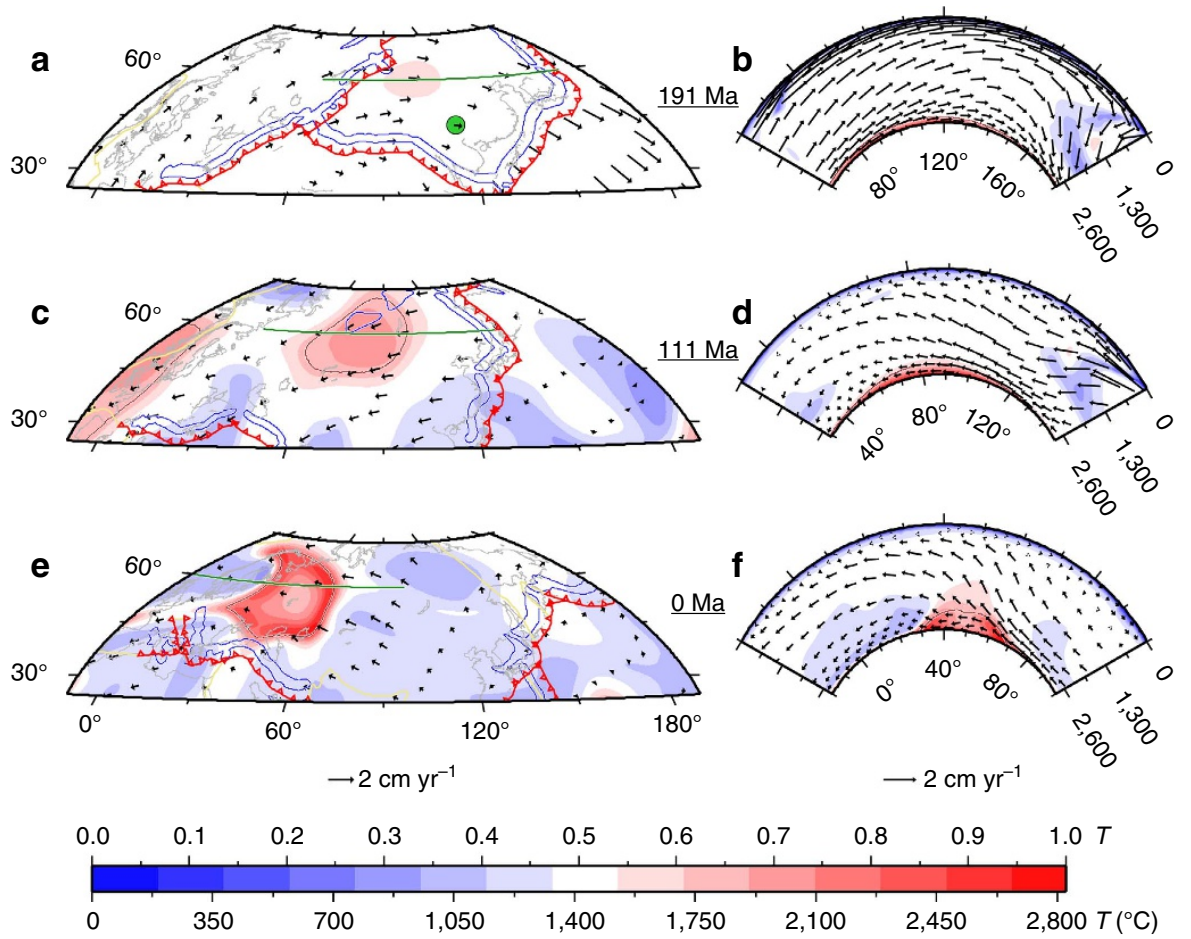

Figure 5 | Formation of the Perm Anomaly. Predicted mantle temperature, flow and composition for case 1 at 2,677 km depth (a,c,e) and along crosssections (green lines) at $60^{\circ}$ latitude (b,d,f). Results are shown at 191 Myr ago (a,b), 111 Myr ago (c,d) and present-day (e,f). Reconstructed subduction locations are shown as red lines with triangles on the overriding plate, reconstructed mid-oceanic ridges and transform faults are shown as yellow lines, and reconstructed coastlines are shown in gray. The brown contours indicate $50 \%$ concentration of dense material. In a,c,e, the blue contours indicate subducting plates with temperature $10 \%$ lower than ambient mantle at $489 \mathrm{~km}$ depth. The green circle in a is the location of the $\sim 258 \mathrm{Myr}$ ago Emeishan LIP, reconstructed at $191 \mathrm{Myr}$ ago.

\section{References}

1. Garnero, E. J. \& McNamara, A. K. Structure and dynamics of Earth's lower mantle. Science 320, 626-628 (2008).

2. Hernlund, J. W. \& Houser, C. On the statistical distribution of seismic velocities in Earth's deep mantle. Earth Planet. Sci. Lett. 265, 423-437 (2008).

3. Lekic, V., Cottaar, S., Dziewonski, A. \& Romanowicz, B. A. Cluster analysis of global lower mantle tomography: a new class of structure and implications for chemical heterogeneity. Earth Planet. Sci. Lett. 357, 68-77 (2012).

4. O'Neill, C., Müller, R. D. \& Steinberger, B. On the uncertainties in hot spot reconstructions and the significance of moving hot spot reference frames. Geochem. Geophys. Geosyst. 6, Q04003 (2005).

5. Steinberger, B. \& Torsvik, T. H. Absolute plate motions and true polar wander in the absence of hotspot tracks. Nature 452, 620-623 (2008).

6. Torsvik, T. H., Burke, K., Steinberger, B., Webb, S. J. \& Ashwal, L. D. Diamonds sampled by plumes from the core-mantle boundary. Nature 466, 352-355 (2010).

7. van der Meer, D. G., Spakman, W., van Hinsbergen, D. J. J., Amaru, M. L. \& Torsvik, T. H. Towards absolute plate motions constrained by lower-mantle slab remnants. Nat. Geosci. 3, 36-40 (2010).

8. Torsvik, T. H. et al. Deep mantle structure as a reference frame for movements in and on the Earth. Proc. Natl Acad. Sci USA 111, 8735-8740 (2014).

9. Dziewonski, A. M., Lekic, V. \& Romanowicz, B. A. Mantle anchor structure: an argument for bottom up tectonics. Earth Planet. Sci. Lett. 299, 69-79 (2010).

10. Burke, K. \& Torsvik, T. H. Derivation of large igneous provinces of the past 200 million years from long-term heterogeneities in the deep mantle. Earth Planet. Sci. Lett. 227, 531-538 (2004).

11. Bunge, H.-P. et al. Time scales and heterogeneous structure in geodynamic Earth models. Science 280, 91-95 (1998).

12. McNamara, A. K. \& Zhong, S. Thermochemical structures beneath Africa and the Pacific Ocean. Nature 437, 1136-1139 (2005).

13. Zhang, N., Zhong, S., Leng, W. \& Li, Z. X. A model for the evolution of the Earth's mantle structure since the Early Paleozoic. J. Geophys. Res. Solid Earth 115, B06401 (2010).

14. Tan, E., Leng, W., Zhong, S. \& Gurnis, M. On the location of plumes and lateral movement of thermochemical structures with high bulk modulus in the 3-D compressible mantle. Geochem. Geophys. Geosyst. 12, Q07005 (2011).
15. Bower, D. J., Gurnis, M. \& Seton, M. Lower mantle structure from paleogeographically constrained dynamic Earth models. Geochem. Geophys. Geosyst. 14, 44-63 (2013).

16. Zhong, S. \& Rudolph, M. L. On the temporal evolution of long-wavelength mantle structure of the Earth since the early Paleozoic. Geochem. Geophys. Geosyst. 16, 1599-1615 (2015).

17. Lynner, C. \& Long, M. D. Lowermost mantle anisotropy and deformation along the boundary of the African LLSVP. Geophys. Res. Lett. 41, 3447-3454 (2014),

18. Long, M. D. \& Lynner, C. Seismic anisotropy in the lowermost mantle near the Perm Anomaly. Geophys. Res. Lett. 42, 7073-7080 (2015).

19. Ni, S., Tan, E., Gurnis, M. \& Helmberger, D. V. Sharp sides to the African superplume. Science 296, 1850-1852 (2002).

20. Wang, Y. \& Wen, L. Geometry and P and S velocity structure of the 'African Anomaly'. J. Geophys. Res. Solid Earth 112, B05313 (2007).

21. Davies, D. R., Goes, S. \& Lau, H. C. P. in The Earth's Heterogeneous Mantle (eds Khan, A. \& Deschamps, F.) 441-477 (Springer, 2015).

22. Davies, D. R. et al. Reconciling dynamic and seismic models of Earth's lower mantle: the dominant role of thermal heterogeneity. Earth Planet. Sci. Lett. 353, 253-269 (2012).

23. Hassan, R., Flament, N., Gurnis, M., Bower, D. J. \& Müller, R. D. Provenance of plumes in global convection models. Geochem. Geophys. Geosyst. 16, 1465-1489 (2015).

24. Steinberger, B. \& Torsvik, T. H. A geodynamic model of plumes from the margins of Large Low Shear Velocity Provinces. Geochem. Geophys. Geosyst. 13, Q01W09 (2012).

25. Bower, D. J., Gurnis, M. \& Flament, N. Assimilating lithosphere and slab history in 4-D Earth models. Phys. Earth Planet. Inter. 238, 8-22 (2015).

26. Jaupart, C., Labrosse, S. \& Mareschal, J. in Treatise on Geophysics: Mantle Dynamics (ed. Bercovici, D.) 253-303 (Elsevier, 2007).

27. Ritsema, J., Deuss, A., van Heijst, H. J. \& Woodhouse, J. H. S40RTS: a degree-40 shear-velocity model for the mantle from new Rayleigh wave dispersion, teleseismic traveltime and normal-mode splitting function measurements. Geophys. J. Int. 184, 1223-1236 (2011).

28. Ritsema, J., McNamara, A. K. \& Bull, A. L. Tomographic filtering of geodynamic models: implications for model interpretation and large-scale mantle structure. J. Geophys. Res. Solid Earth 112, B01303 (2007). 
29. Torsvik, T. H., Müller, R. D., van der Voo, R., Steinberger, B. \& Gaina, C. Global plate motion frames: toward a unified model. Rev. Geophys. 46, RG3004 (2008).

30. Simmons, N. A., Forte, A. M., Boschi, L. \& Grand, S. P. GyPSuM: a joint tomographic model of mantle density and seismic wave speeds. J. Geophys. Res. Solid Earth 115, B12310 (2010).

31. Fritzell, E. H., Bull, A. L. \& Shephard, G. E. Closure of the Mongol-Okhotsk Ocean: insights from seismic tomography and numerical modelling. Earth Planet. Sci. Lett. 445, 1-12 (2016).

32. Seton, M. et al. Global continental and ocean basin reconstructions since 200Ma. Earth-Sci. Rev. 113, 212-270 (2012).

33. Müller, R. D. et al. Ocean basin evolution and global-scale plate reorganization events since pangea breakup. Annu. Rev. Earth Planet. Sci. 44, 107-138 (2016).

34. Ford, H. A., Long, M. D., He, X. \& Lynner, C. Lowermost mantle flow at the eastern edge of the African Large Low Shear Velocity Province. Earth Planet. Sci. Lett. 420, 12-22 (2015).

35. Torsvik, T. H., Steinberger, B., Gurnis, M. \& Gaina, C. Plate tectonics and net lithosphere rotation over the past 150My. Earth Planet. Sci. Lett. 291, 106-112 (2010).

36. Helmberger, D. V. \& Ni, S. in Earth's Deep Mantle: Structure, Composition, and Evolution Vol. 160 Geophysical Monograph Series 63-81 (American Geophysical Union, 2005).

37. Domeier, M. \& Torsvik, T. H. Plate tectonics in the late Paleozoic. Geosci. Front. 5, 303-350 (2014).

38. Kustowski, B., Ekström, G. \& Dziewoński, A. M. Anisotropic shear-wave velocity structure of the Earth's mantle: a global model. J. Geophys. Res. Solid Earth 113, B06306 (2008).

39. Zhong, S., McNamara, A., Tan, E., Moresi, L. \& Gurnis, M. A benchmark study on mantle convection in a 3-D spherical shell using CitcomS. Geochem. Geophys. Geosyst. 9, Q10017 (2008).

40. Gurnis, M. et al. Plate tectonic reconstructions with continuously closing plates. Comput. Geosci. 38, 35-42 (2012).

41. Stadler, G. et al. The dynamics of plate tectonics and mantle flow: from local to global scales. Science 329, 1033-1038 (2010).

42. Flament, N. et al. Topographic asymmetry of the South Atlantic from global models of mantle flow and lithospheric stretching. Earth Planet. Sci. Lett. 387, 107-119 (2014)

43. MacQueen, J. in Proceedings of the Fifth Berkeley Symposium on Mathematical Statistics and Probability 281-297 (Oakland, CA, USA, 1967).

44. Forte, A. M. \& Mitrovica, J. X. Deep-mantle high-viscosity flow and thermochemical structure inferred from seismic and geodynamic data. Nature 410, 1049-1056 (2001).

45. Steinberger, B. Effects of latent heat release at phase boundaries on flow in the Earth's mantle, phase boundary topography and dynamic topography at the Earth's surface. Phys. Earth Planet. Inter. 164, 2-20 (2007).

46. Mégnin, C. \& Romanowicz, B. A. The three-dimensional shear velocity structure of the mantle from the inversion of body, surface and higher-mode waveforms. Geophys. J. Int. 143, 709-728 (2000).

47. Houser, C., Masters, G., Shearer, P. \& Laske, G. Shear and compressional velocity models of the mantle from cluster analysis of long-period waveforms. Geophys. J. Int. 174, 195-212 (2008).
48. Auer, L., Boschi, L., Becker, T. W., Nissen-Meyer, T. \& Giardini, D. Savani: a variable resolution whole-mantle model of anisotropic shear velocity variations based on multiple data sets. J. Geophys. Res. Solid Earth 119, 3006-3034 (2014).

49. French, S. W. \& Romanowicz, B. A. Whole-mantle radially anisotropic shear velocity structure from spectral-element waveform tomography. Geophys. J. Int 199, 1303-1327 (2014).

\section{Acknowledgements}

This research was undertaken with the assistance of resources from the National Computational Infrastructure (NCI), which is supported by the Australian Government. N.F. and R.D.M. were supported by ARC IH130200012. S.W. was supported by SIEF RP 04-174. M.G. and D.J.B. were supported by Statoil ASA and by the NSF under grants CMMI-1028978, EAR-1161046 and EAR-1247022. Figures were constructed using the Generic Mapping Tools and matplotlib. We thank T.C.W. Landgrebe for advice in calculating accuracy and sensitivity, D. Steinberg for advice on cluster analysis, J. Ritsema for sharing the seismic filter for S40RTS, and three anonymous reviewers for comments that improved the quality of the manuscript.

\section{Author contributions}

N.F. ran and analysed the models, S.W. instigated the study and implemented the cluster analysis, R.D.M. and M.G. developed the concepts of the study and D.J.B., M.G. and N.F. developed the framework to assimilate tectonic reconstructions in CitcomS. All authors contributed to the writing of the manuscript, led by N.F.

\section{Additional information}

Competing financial interests: The authors declare no competing financial interests.

Reprints and permission information is available online at http://npg.nature.com/ reprintsandpermissions/

How to cite this article: Flament, N. et al. Origin and evolution of the deep thermochemical structure beneath Eurasia. Nat. Commun. 8, 14164 doi: 10.1038/ncomms14164 (2017).

Publisher's note: Springer Nature remains neutral with regard to jurisdictional claims in published maps and institutional affiliations.

(c) (i) This work is licensed under a Creative Commons Attribution 4.0 International License. The images or other third party material in this article are included in the article's Creative Commons license, unless indicated otherwise in the credit line; if the material is not included under the Creative Commons license, users will need to obtain permission from the license holder to reproduce the material. To view a copy of this license, visit http://creativecommons.org/licenses/by/4.0/

(C) The Author(s) 2017 